\title{
A Design of Evaluation Framework for the Assets and Insolvency Prediction Depending on the Industry Type Using Data Standardization based on the Forensic Readiness
}

\author{
Jaechun Kim, Youngjun Son and Mokdong Chung \\ Dept. of Computer Engineering in Pukyong National University \\ k971110@hanmail.com,say4ever@empas.com and mdchung@pknu.ac.kr
}

\begin{abstract}
In this paper, analysis scenario, detection and risk and the negative risk classification and measurement industry through Analysis of data for types of topics, including through change according to the situation in Predictive Evaluation and Monitoring Forensic by designing ICANN-based frame based, focusing the arrangements. The proposed system is business through links to the existing legacy systems and operates in the insolvency of corporate assets and the Predictive Evaluation of operational, the firm's assets by managing, and Risk Management for efficient and reliable support for such assets, management and recovery for by business interests can be enhanced. Also Forensic data to utilize an analysis, monitoring the standardization of arrangements are based also, Min, Protos, or corporate disputes such as criminal proceedings for gathering evidence through the data. It can prevent accidents and civil affairs and others, we can provide. For corporations as well as the situation of the Enterprise during system operation and can be verified by analysis of data, by providing the framework that can provide cost, and Software reuse can do.
\end{abstract}

Keywords: Data Standardization, Forensic Readiness, Assets and Insolvency Prediction

\section{Introduction}

In order to sustain long-term stable growth in the field of different industries, business environment and the changes with respect to the structure of the efforts to predict and respond correctly and quickly is essential. Is the future of each industry to predict in advance of the changes in the environment and could only be continually improve and expand it responded properly. Every industry types about the various environment exists and such an environment, information and expert evaluations, using the current business environment tend to use in analyzing and predicting The changing circumstances of each industry type of situation analysis and forecasting model about the research is needed [2].

Prediction in Evaluation of bad debts, assets and people also have hosted or intuition is to create and use the models so they can reflect and to the purpose of the majority, but At the same time the uncertain situation, and can be taken into consideration should be clearly explained and decision makers would simply an objective that can use predictive analysis approach is needed [1].

Korea`s corporate forensics, readiness for the concept, implementation and for the practice of a case in point, and there is no forensics and legal systems for readiness current policy has been a marginal state. Also, systematic effort and not legal provisions exist for Forensic readiness of privacy, forensics, because there is no readiness prior to the basic reaction to the events system They also provided do not even. 
The latest data emerges as key elements of the strategic decision of the companies realize the increasing interest on the quality of data integration and data. In order to ensure the quality of data is inevitably must involve the standardization of data.

However, data utilization have data on occurrence and means for data capture and data on the organization, processes and systems in the repetition of the discrepancy delays in timely provision of information Difficulties of integration, data and information system changes and lack of maintenance problems, obstacles have been unabated.

Enterprise support system of the enterprise (enterprise resources planning) resulting from the adoption of management information, mutual relevance of the rise and secure competitiveness through IT companies ' assets, And risk management, efficiency and long-term financial planning and integration of the need for a system that can do that, being raised.

Section 2 looks at related work. In Section 3, we introduce the proposed system with forensic readiness. Section 4 draws conclusion and discusses future work.

\section{Related Work}

\subsection{Standardization of Data}

2.1.1. Need for Standardization of Data: By overlapping, systems of data and data discrepancies as practical use according to the problem of the data classification, currently, data for the city hard time figuring out, etc., and the data quality and meaning For the standard issue in a variety of development information systems, data management staff member killed in action, tools, lack of tools, etc. The importance of data and corporate strategic decision making in common and standardization activities is needed. In addition, the unification of data standardization, names due to communicate clearly caused, and enhance a consistent data format and rules due to the application of data quality gains might be given.

2.1.2. Data Standardization Concepts: System of few scattered data, information element for the designation, type, format, and to establish principles for rules, it means to apply by enterprise, and of data. You can understand the exact meaning, and data that adjust the contrasting views about the role.

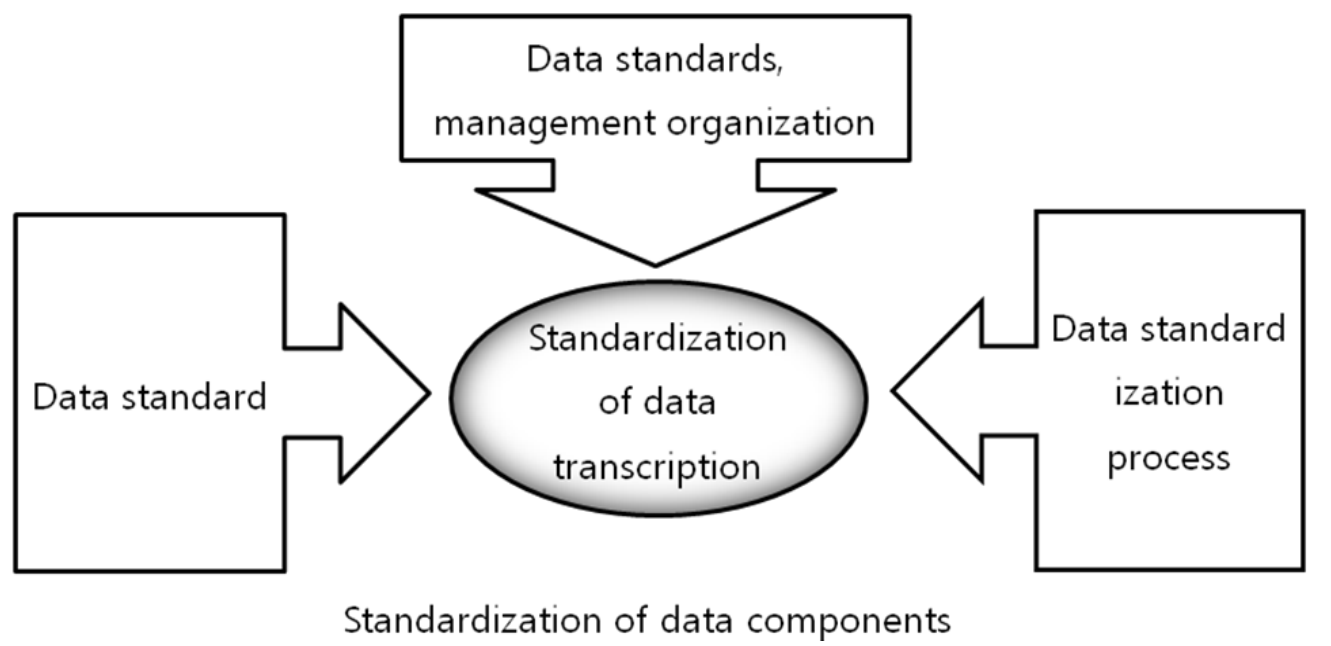

Figure 1. Standardization of Data Components

2.1.3. Data Standard Management Tool: Enterprise Data standards, which had been established by management of information and data standards development and 
maintenance support, data standards, compliance and change impact, which is responsible for evaluation by function All meta data, configuration management function, along with standard data and applications information query functions about have introduced a system of utilization.

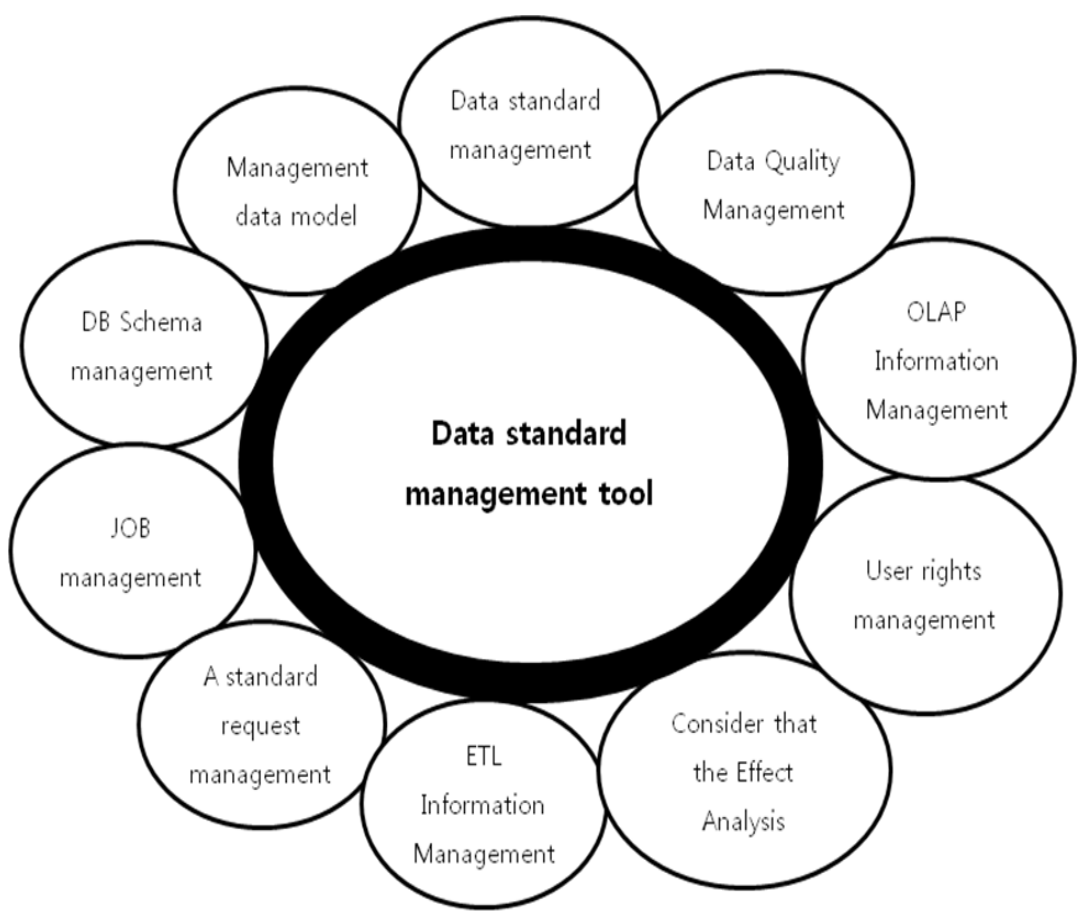

System Configuration Management Data standards

Figure 2. System Configuration Management Data Standards

\subsection{Forensic Readiness}

Forensic Readiness is frequently detecting a cyber-accident occurrence before it happens, and a system to prepare obligatorily establishment policy to maximize analysis capability and collecting the evidence when it happens. The organization's internal tool components of forensic readiness are operating system of the information management, electronic ID, electronic signature, and DRM utilities. Technical components are proactive monitoring, logging security events, time synchronization, policy-based system with forensic readiness, life cycle management techniques, and record search mechanism. However, it requires to secure a legal evidence can be guaranteed that the state needs the integrity of the evidence collected, authenticity, integrity, and reliability including the results of the log or monitored unlike existing information protection requirements [4].

\subsection{Corporate Fraud Risk Management}

Corporate fraud means all harmful and undependable actions as workers go against company hindering from creating profits which is the essential goal to the company. Especially, it is defined as corporate financial damage and risk directly.

Forensic readiness architecture in SAIP consists of main process, sub process, and SAIP container. Main process is classifying, detecting, analyzing and treating illegal risk. Sub process shows more specific items of main process. SAIP container as forensic component is establishing concrete rules for fraud, and collecting digital evidence through monitoring and collecting data forensically. 


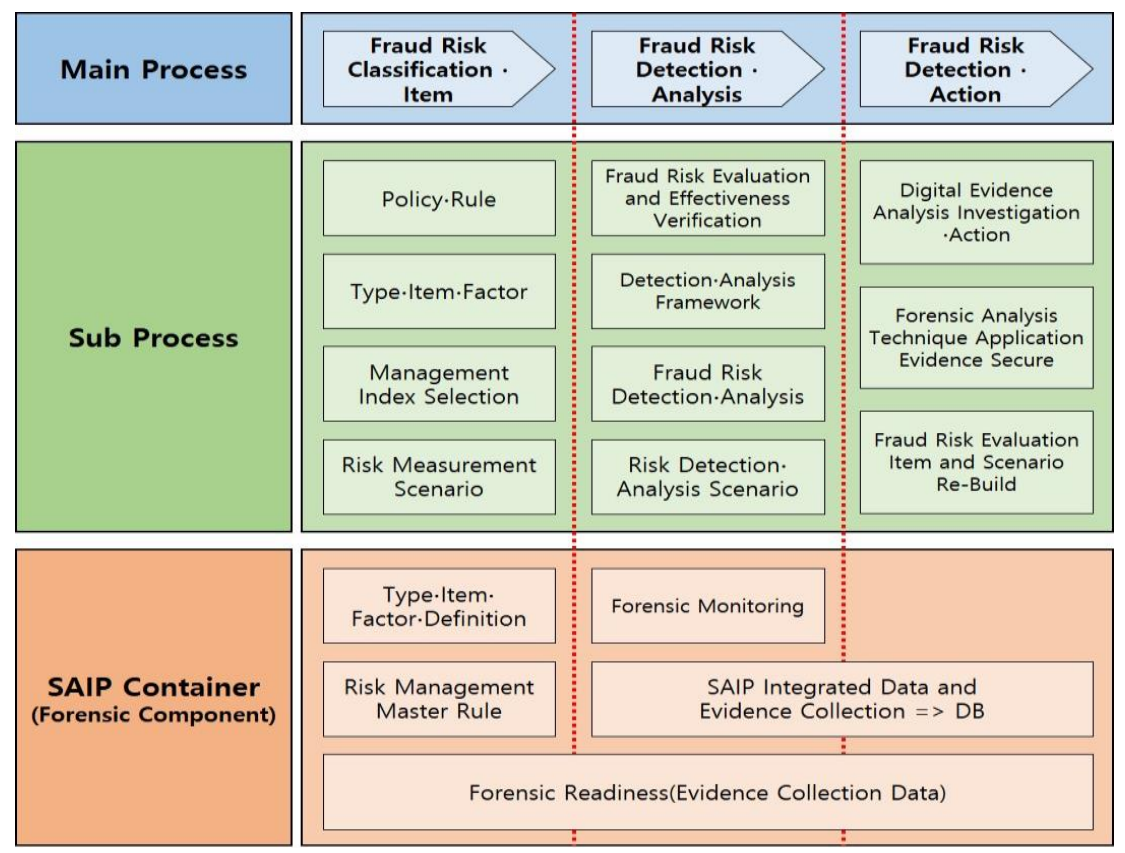

Figure 3. Forensic Readiness Architecture in SAIP

\subsection{SAIP (System for Assets and Insolvency Prediction)}

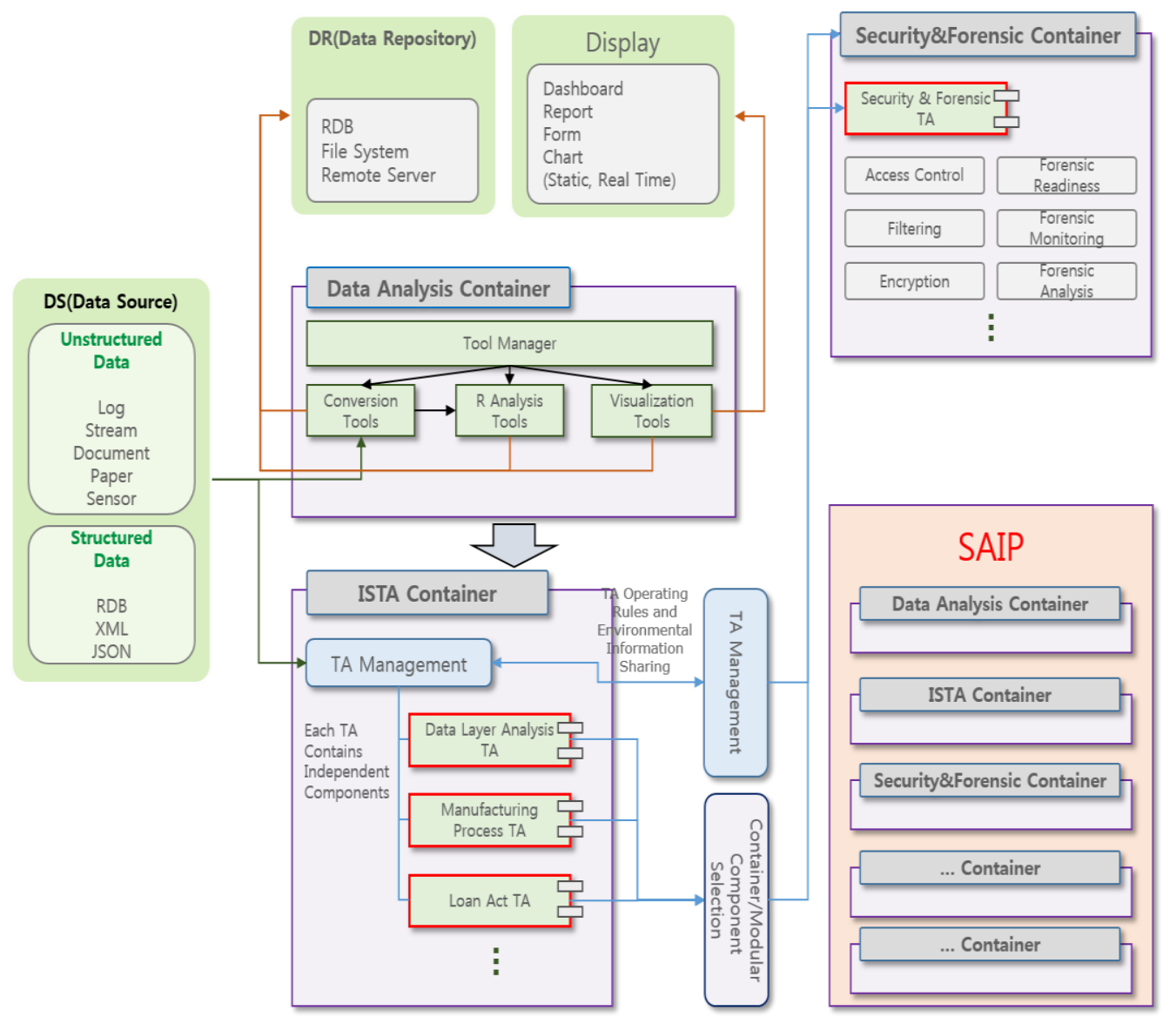

Figure 4. Overall Architecture of SAIP 


\section{Design and Implementation of the Proposed System}

\subsection{Proposed System of Architecture}

The proposed FORESTA (Forensic Technical Architecture) framework is composed of big data converter container, analysis and verification container, ISTA (Industry Sector Technical Architecture) container and forensic readiness container. Big data converter container collects unstructured data such as working environment information from IOT devices, raw data, production data and the specific data according to an industrial type and the container converts the unstructured data to structured format. Analysis and verification container analyzes and verifies the structured data using the $\mathrm{R}$ statistical tool, design of experiment and machine learning techniques. ISTA container generates a standardized TA in accordance with an industrial type and field. Forensic readiness container detects and analyzes fraud risk that may be encountered and the container collects digital evidences that are related to lawsuits, disputes, complaints, etc.

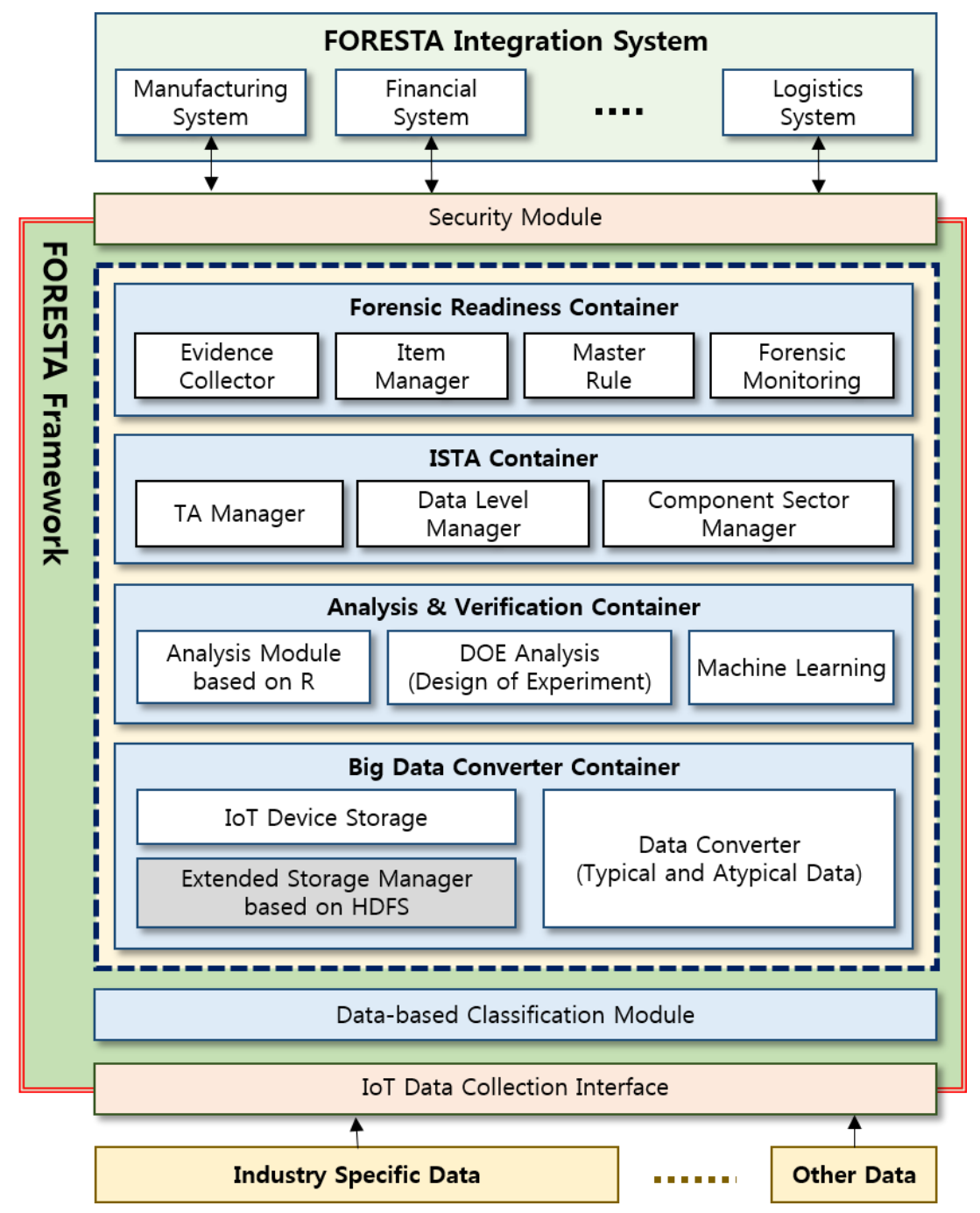

Figure 5. FORESTA Framework

\subsection{Dataflow of the Proposed System}

The algorithm of the proposed system is composed of 5 stages. First, collect customers' diverse requirements from surveys according to industrial types such as manufacturing, financial, retail, etc., and design the requirement analysis TA through customization. 
Second, convert the obtained data to the database format which is suitable for SAIP. Third, analyze the measurement list through mean variables of research group and weight values determined from AHP technique, which is one of multi-criteria decision making models. Fourth, apply standard TA from the analyzed assessment items to SAIP. Fifth, construct databases about fraud risks such as disputes, financial incidents and infringement of the personal information through forensic readiness component. And design new TA again from log data, transactions and post management which are generated in web system management.

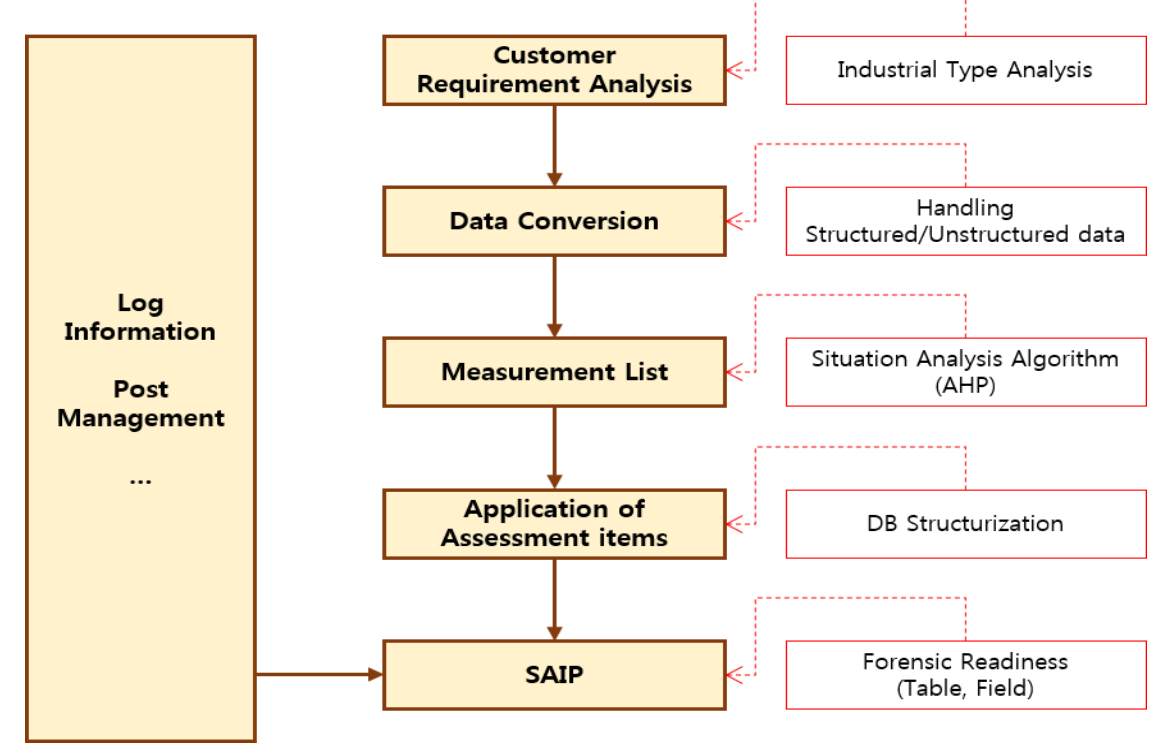

Figure 6. Dataflow of the Proposed System

\subsection{Forensic Monitoring Scenario}

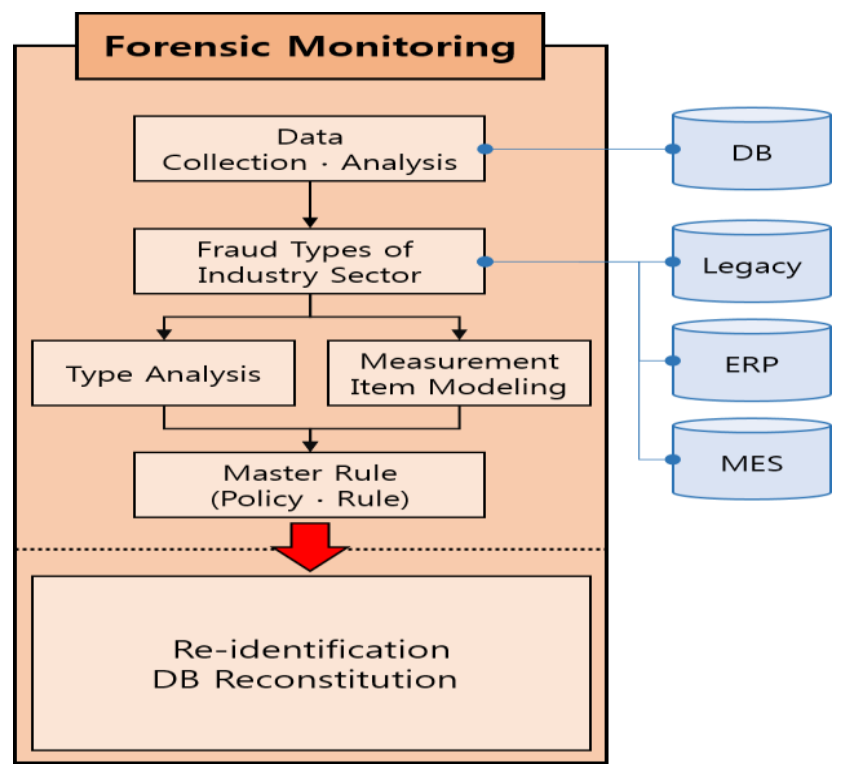

Figure 7. Forensic Monitoring Component in SAIP

SAIP's forensic monitoring component builds a modeling about common types of fraud industry sector after collecting and analyzing data and analysis. And it constructs standard framework with gathering evidences in accordance with policy and rule. Lastly, it 
identifies problems and reconstitutes database. Figure 7 shows forensic monitoring component.

3.3.1. Data Collection and Analysis: When someone registers as a user on SAIP, he or she sets up a standard TA, code, and screen. Afterward also he or she sets up a database that is suitable for forensic readiness through object modularization about measurement list for AHP (Analytic Hierarchy Process) analysis on the screen [5].

3.3.2. Types of Fraud Industry Sector: Because there are many fraud types according to industrial features, it is needed to classify in advance. Examples of common types of industrial fraud are as follows [6].

(a) Manufacturing

- Management's distortion and off-balance sheet assets, liabilities missing with fictional sales

- Designate conversion of non-performing loan after misuse a credit account and bad account disposal

- Misuse public money with manipulating ready money

- Purchase, Accounts Master File information false registration and tampering

- Illegal hiding by manipulation of computerized data

(b) Finance

- Unreasonably withdrawals of large amount with non-fundamental computerized trading

- Arbitrarily separation adjustment of loan fitted limit right to graduates

- Arbitrary access to Customer Information Management System and manipulating related information

- Distortion of analysis about investment risk of financial asset management

We analyzed and extracted the entries that disputes, criminal/civil litigation, complaints may occur according to industry types. Table 1 and 2 shows the forensic readiness entries for manufacturing and finance industry area.

\section{Table 1. Forensic Readiness for Manufacturing (Mold and Coating} Formulation)

\begin{tabular}{|c|c|c|c|c|c|}
\hline $\begin{array}{c}\text { Raw } \\
\text { Materials } \\
\end{array}$ & $\begin{array}{c}\text { Raw } \\
\text { Material Input }\end{array}$ & $\begin{array}{c}\text { Mold } \\
\text { Maintenance }\end{array}$ & Molding & $\begin{array}{r}\text { Inspection } \\
\text { Management }\end{array}$ & $\begin{array}{r}\text { Packaging } \\
\text { and Shipping }\end{array}$ \\
\hline $\begin{array}{l}\text { import } \\
\text { inspection } \\
\text { storage } \\
\text { grinding } \\
\text { and } \\
\text { pressing } \\
\text { mixing \& } \\
\text { drying }\end{array}$ & $\begin{array}{l}\text { - supply } \\
\text { storage } \\
\text { management } \\
\text {-adequacy of } \\
\text { supply } \\
\text { method }\end{array}$ & $\begin{array}{l}\cdot \text { mold signed } \\
\cdot \text { mold PM } \\
\text { cycle } \\
\cdot \text { temperature } \\
\text { control } \\
\text { metal } \\
\text { detection } \\
\text { management }\end{array}$ & $\begin{array}{l}\text { condition } \\
\text { manageme } \\
\text { nt } \\
\text { product- } \\
\text { specific } \\
\text { optimal } \\
\text { condition }\end{array}$ & $\begin{array}{l}\cdot \text { external \& } \\
\text { dimensions } \\
\text { function } \\
\text { inspection } \\
\text {-product } \\
\text { management }\end{array}$ & $\begin{array}{l}\text { packaging } \\
\text { specification } \\
\text { s } \\
\text { - container } \\
\text { label \& LOT } \\
\text { \& inventory } \\
\text { management }\end{array}$ \\
\hline \multicolumn{6}{|c|}{$\begin{array}{l}\text {, sensor data, etc. } \\
\text { tion, product LOT number, o }\end{array}$} \\
\hline
\end{tabular}




\section{Table 2. Forensic Readiness for Finance (Bond Management)}

\begin{tabular}{|c|c|c|c|c|c|}
\hline $\begin{array}{l}\text { Authenticat } \\
\text { ion }\end{array}$ & $\begin{array}{l}\text { Transacti } \\
\text { on } \quad \text { Ledger }\end{array}$ & $\begin{array}{l}\quad \text { Assets and } \\
\text { Insolvency } \\
\text { Prediction }\end{array}$ & $\begin{array}{l}\text { Assets and } \\
\text { Bonds } \\
\text { Management }\end{array}$ & $\begin{array}{l}\text { Accounting } \\
\text { Business } \\
\text { Management }\end{array}$ & $\begin{array}{l}\text { Materia } \\
\text { Offer }\end{array}$ \\
\hline $\begin{array}{l}\text { - bonds } \\
\text { contract } \\
\text { - debt } \\
\text { reduction } \\
\text { - delegation } \\
\text { lawsuit } \\
\text { - legal costs }\end{array}$ & $\begin{array}{l}\text { loan } \\
\text { balance } \\
\text { - elapse of } \\
\text { prescription } \\
\text { incident } \\
\text { loans }\end{array}$ & $\begin{array}{l}\cdot \text { completion of } \\
\text { extinctive } \\
\text { prescription } \\
\text { - bonds types } \\
\text { - unrecoverable } \\
\text { bonds }\end{array}$ & $\begin{array}{l}\text { - debt } \\
\text { settlement } \\
\text { - exclusion } \\
\text { period } \\
\text { - post } \\
\text { management }\end{array}$ & $\begin{array}{l}\text { recovery } \\
\cdot \text { billing costs } \\
\cdot \text { legal costs }\end{array}$ & $\begin{array}{l}\text { - litigation } \\
\text { materials } \\
\text { - law firm } \\
\text { - customer }\end{array}$ \\
\hline \multicolumn{6}{|c|}{$\begin{array}{l}\text { Process diverse data such as legacy databases, accounting data, network, etc. } \\
\text { Legal disputes which can be caused by withdrawal of bonds such as legal prescription, } \\
\text { reduction } \\
\text { Forensic monitoring for financial incident such as complaints, misappropriation, misuse } \\
\text { etc. }\end{array}$} \\
\hline
\end{tabular}

Also, SAIP applied each measurement item to industrial disputes and fraud risk factors through requirement analysis [6]. And it has the combination function which reconstructs the databases table and field of forensic readiness for fraud risk detection and analysis. Figure 8 shows the screenshot of forensic readiness component in SAIP.

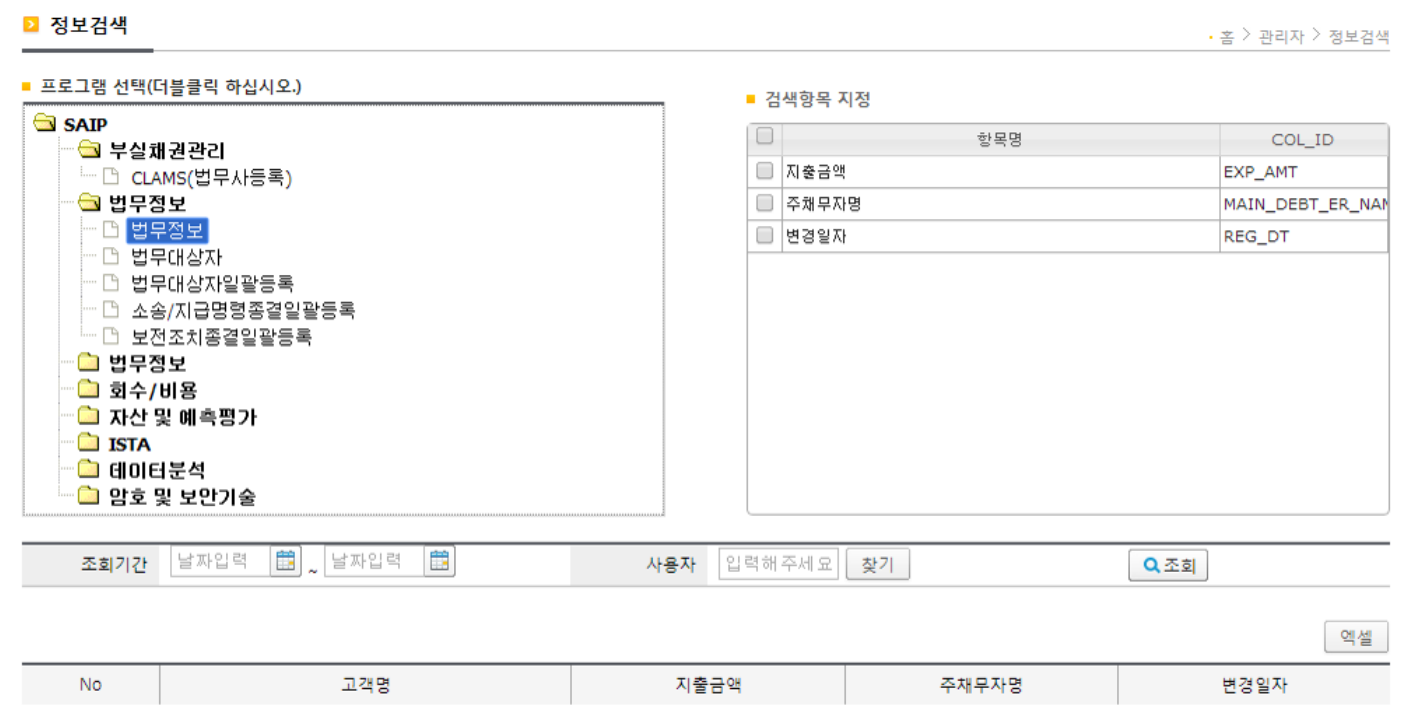

Figure 8. Combination Function of Forensic Readiness Component

\subsection{Benefits of Data Standardization}

The data standardization provides the consistency of data names, formats and rules. Therefore it may contribute to the competitiveness of the enterprise through the increased accuracy of communication, decreased cost and time to process data, improved data quality and easy data exchange. Table 3 shows the benefits of the proposed framework in qualitative, quantitative and application plan aspects. 
Table 3. Benefits of the Proposed Framework

\begin{tabular}{|c|c|c|}
\hline Qualitative aspects & Quantitative aspects & Application \\
\hline $\begin{array}{l}\text { Software reuse as } \\
\text { maximizing the use } \\
\text { of standardized processes }\end{array}$ & $\begin{array}{l}\text { Deployment of re-use libraries, } \\
\text { due to optimizing the framework } \\
\text { component }\end{array}$ & $\begin{array}{l}\text { Data converter have their } \\
\text { own API }\end{array}$ \\
\hline $\begin{array}{l}\text { Data analysis results } \\
\text { in ensuring the credibility and } \\
\text { objectivity }\end{array}$ & $\begin{array}{l}\text { Analysis of industry standards for } \\
\text { types of the procurement process }\end{array}$ & $\begin{array}{l}\text { Establish high level } \\
\text { architecture }\end{array}$ \\
\hline $\begin{array}{l}\text { Distributed processing data due } \\
\text { to big data storage and } \\
\text { maintenance }\end{array}$ & $\begin{array}{l}\text { Compatibility of the government } \\
\text { standard } \\
\text { framework }\end{array}$ & $\begin{array}{l}\text { Development of FORESTA } \\
\text { framework } \\
\text { (IOT App, NPL App, } \\
\text { Distribution App, etc.) }\end{array}$ \\
\hline $\begin{array}{l}\text { Monitoring by the preliminary } \\
\text { forensics evidence collection }\end{array}$ & $\begin{array}{l}\text { A foundation for secure data } \\
\text { management support }\end{array}$ & $\begin{array}{l}\text { Have prepared for } \\
\text { the forensics } \\
\text { database }\end{array}$ \\
\hline
\end{tabular}

\section{Conclusion}

Forensic Analysis Model for Evaluation and Prediction of non-performing assets by a industry not subject to readiness Type in this paper design can make it safer, and the asset management of the business of non-performing loans. The return rate through prevention and management of corporate profits led the increase can be achieved to maximize. In addition, forensic company utilized its readiness of Dispute Prevention Office, and to collect evidence at the service industries which can be the violations of personal accident prevention and prevention by Type Framing the Prediction of measurement can the objective through a trust, through the item. Data conversion and customer needs by compiling the data produced on the integrated system of standards that can be satisfied with colorful variety through such newly created business analysis and presents the Guidance document for the operation and management of the benefit is that they can do. Modular plug-in) in the form of a common system (each container is a proposal by the addition of a has enabled as easily, and support cloud-based Web as it so is able to bring the effect of cost reduction. Modular platforms based on the service sector was developed for future studies that fit the situation by expanding manufacturing industries such as improved functionality and the law firm, ta, designing Provincial data through the preparation of forensic collection and digital forensic analysis of data collected by applying at Standard presented the architecture and objective that can be to test their skills to the study. I wish to emphasis.

\section{Acknowledgements}

This work (Grants No. C0146737) was supported by Business for Cooperative R\&D between Industry, Academy, and Research Institute funded Korea Small and Medium Business Administration in 2013.

\section{References}

[1] S. Baek and J. Lim, "A Study on the Forensic Readiness as an Effective Measure for Personal Information Protection", Internet and Information Security 3 (2012), pp. 34-64.

[2] J. Park, D. Jang, and G. Nam, "ERP Adoption of Insurance Business and Its Effects on Risk Management System", The e-Business Studies 13 (2012), pp. 115-137.

[3] Legislative Hearings Kit for Privacy Statement and Prevention of Damage Spreading, Future Planning, Science, Broadcasting \& Communications Committee (2014); http://act.jinbo.net/drupal /sites/default/files/(\%EC\%B5\%9C\%EC\%A2\%85).pdf

[4] Digital Forensic Practice, Korea Information Processing Society, Short-Term Lecture 3 (2012).

[5] K. Eizo and O. Takao, "Strategic decision-making technique AHP", Cheongram Publications (2012). 
[6] The concept and prevention of corporate fraud; http://www.seri.org/fr/fPdsV.html?fno=002152 \&menucode $=0499 \&$ gubun $=40 \&$ no $=000412$

[7] J. Kim and M. Chung, "Cloud-based Integrated Support System for the Bond Management using AHP technique", Proc. Of KIISE Symposium 6 (2012), pp.169-172.

[8] B. Lee, J. Park, and J. Yoo, "Implementation of Data processing of the High Availability for Software Architecture of the Cloud Computing, Journal of the Korean Contents Association 3(2013), pp. 32-43.

[9] Strategic Risk Management Methodology; http://cfile221.uf.daum.net/attach/110C2C0D4 98FA0041707D2

[10] J. Kim, Y. Son and M. Chung, "Forensic Readiness applied to System for Assets and Insolvency Prediction", The Proc. of the 9th Int'l Conf. on Multimedia Information Technology and Applications (2014), pp. 166-169.

[11] T. L. Saaty, "The Analytic Hierarchy Process", McGraw-Hill, New York publication (1980).

[12] G. Seo, "The guide for Data Architecture Professional", Korea Database Agency (2013).

\section{Authors}

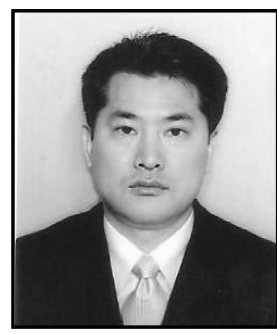

\section{Jaechun Kim,}

2002: BS in Computer Engineering, Dongseo University 2007: MS in Computer Engineering, Pukyong National University 2009 Present: Ph.D Candidate, Computer Engineering, Pukyong National University 2014 Present: Representative Director of Nara System cofi.

Research Interests: Digital Forensics, R statistical analysis, Big Data and Asset Management

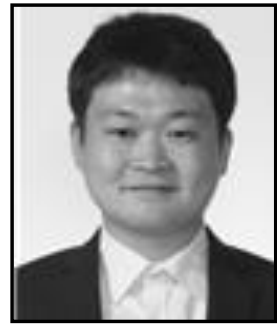

Youngjun Son, 2009: BS in Police Administration, Korea National Police University 2014: MS in Computer Engineering, Pukyong National University Research Interests: Digital Forensics and Data Mining

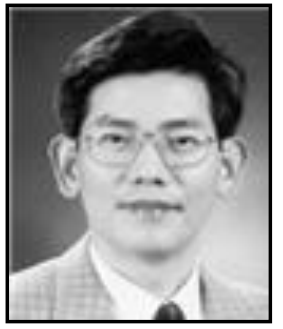

Mokdong Chung, 1981: BS in Computer Engineering, Kyungpook National University 1983: MS in Computer Engineering, Seoul National University 1990: Ph.D in Computer Engineering, Seoul National University 1985 1996: Professor, Department of Computer Engineering, Pusan University of Foreign Studies

1996 Present: Professor, Department of Computer Engineering, Pukyong National University

Research Interests: Digital Forensics, OOP technology, Computer Security for Application, Intelligent Agent and Context Aware Computing 